\title{
AN ARTIFICIAL NEURAL NETWORK PREDICTION MODEL FOR FIRE RESISTANCE OF COMPOSITE COLUMNS
}

\author{
Marijana Lazarevska* \\ Faculty of Civil Engineering, University of Skopje, Skopje, Macedonia \\ Milivoje Milanović \\ State University of Novi Pazar, Novi Pazar, Serbia \\ Dr Miloš Knežević \\ Faculty of Civil Engineering, University of Podgorica, Podgorica, Montenegro \\ Dr Meri Cvetkovska \\ Faculty of Civil Engineering, University of Skopje, Skopje, Macedonia \\ Ana Trombeva Gavriloska \\ Faculty of Civil Engineering, University of Skopje, Skopje, Macedonia \\ Dr Todorka Samadzioska \\ Faculty of Architecture, University of Skopje, Skopje, Macedonia
}

An artificial neural network prediction model for fire resistance of centrically loaded composite columns exposed to fire from all sides is presented in this paper. Three different types of composite columns, as: totally encased, partially encased and hollow steel sections filled with concrete, as well as ordinary $R C$ columns were analyzed by using the program FIRE. The effects of the shape, the cross sectional dimensions and the intensity of the axial force were analyzed. The results of the performed analyses were used as input parameters for training the neural network prediction model.

Key words: Artificial neural network, Prognostic model, Fire resistance, Composite columns

\section{INTRODUCTION}

The legally prescribed time period during which a structure must stay stabile and safe under fire, is actually the time in minutes which represents the fire resistance of a structure. The length of this time period is obligatory in almost every country and it depends on: the height, number of flats, floor area, capacity, content and purpose of the structure, the distance of fire stations and fire brigades, as well as on the fire protection system of the structure [01].

The fire resistance of a structure can be determined based on the estimated fire resistance of whole structure or of each structural element (columns, beams, slabs, walls etc.). The fire resistance of a structural element is the time period (in minutes) from the beginning of the fire until the moment when the element reaches its ultimate capacity (ultimate strength, stability and deformability) or until the element loses its separation function [01].

Nowadays, as a result of many years of investigations, there are three basic methods for determination the fire resistance of structural elements. The oldest method is the performance of a fire test of loaded element, the second method implies the use of empirical formulae that are based on the results from performed fire tests and the third method is based on analytical approach and anables not only design of elements but of whole structures with a predefined fire resistance and it is based on the principles of structural mechanics and theory of heat transfer [01].

For the last twenty years, particular importance has been given to analytical definition of the problem, but the need for getting answers to many questions in this field implies the application of new, modern and faster methods for determining the fire resistance of structures. The application of neural networks as such a method for building a prognostic model which can be used for predicting the fire resistance for structures and/or their elements is of a huge importance for the design process in construction [06], [07].

The goal of the research presented in this paper was to build a prognostic model which could gener- 
ate outputs for the fire resistance of centrically loaded composite steel-concrete columns for any given input data, by using the numerical results from the existing research program, as input data.

\section{FIRE RESISTANCE OF STEEL-CONCRETE COMPOSITE COLUMNS}

The columns, as structural elements, have an important role in preventing loss of global stability of structures under fire. If these elements do not suffer failure, damages shall be of a local character. The idea for the construction of the composite structures as combination of the two traditional materials, concrete and steel, is based on the effective use of the advantages of both materials. Even before the first composite columns were constructed, the steel columns were encased in concrete to achieve higher fire resistance. This paper presents the numerically achieved results for the fire resistance of centrically loaded steelconcrete composite columns with different cross sections, as: concrete filled hollow steel section CFS, partially encased steel section PES and totally encased section TES (Figure 1). For comparison a reinforced concrete column (RC) has also been analyzed (as reference one) because it has high fire performance. The columns with fixed-pinned support conditions and exposed to standard fire ISO 834 from all four sides were analyzed by using the computer program FIRE (Fire Response - Cvetkovska 2002). The influence of the shape of the cross section (different types of cross sections), cross sectional dimensions $(30 \times 30,30 \times 50$, and $40 \times 40)$ and the intensity of the axial force were analysed. The axial load ratio, which is ratio between the applied axial force $\mathrm{N}$ and the ultimate force $\mathrm{Nu}$, was varied from 0,1 to 0,5 .

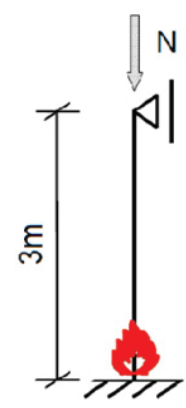

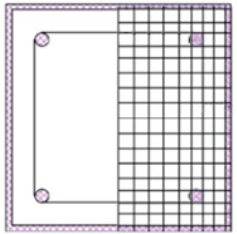

a) CFS

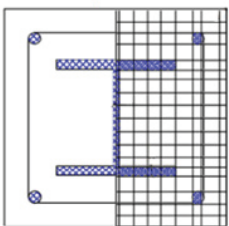

c) TES

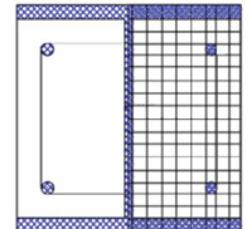

b) PES

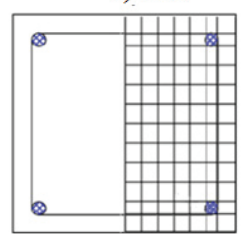

d) $\mathrm{RC}$
Figure 1: Geometry and support conditions, discretization and cross section geometry

\section{NEURAL NETWORK PROGNOSTIC MODEL}

The goal of the investigation presented in this paper was to build a prognostic model that could generate outputs for the fire resistance of centrically loaded steel concrete composite columns by using the numerical results as input data.

The neural network prediction model was developed by using the software Neural Tools ver.6. The numerical results given in [02] were used as input data and all data were grouped into two separate tables: the data for training and testing the neural network and data for predicting the value of the output variable. During that training process a total of 87 cases were analyzed, 70 $(80 \%)$ of which belong to the group of cases for training and the rest 17 cases $(20 \%)$ were used for testing the network. The following four independent variables were treated as input data: dimensions of the cross section of the column (a and $b$ ), loading coefficient ( $\alpha$ ) as ration between the applied axial force and the ultimative axial force and type of the column (concrete filled hollow steel sections CFS, partially encased steel sections PES, totally encased steel sections TES and reinforced concrete sections RC, as reference one). The output was only one variable: the fire resistance of the column expressed in minutes (t).

Training and testing of the neural networks is an iterative process that repeats the procedure of training and testing of several neural networks with different structure until it generates neural network which provides the best outcomes [38]. For the multilayered networks with spreading the information forward (in one direction, from input to output layer) the learning cycle means determination of weight coefficients for the connections between neurons, where training is a smart choice of weight coefficients that get the best predictions [4-9]. Training stops at the moment when it reaches one of the three conditions defined by the user, namely: the maximum time required for training, the number of training cycles, or the change of the error at certain time.

Assessment of prediction accuracy of neural networks is done by comparing the following parameters [10]:

- Percentage of bad predictions - denotes the number of cases whose predicted value does not match the expected value, i.e. the predicted value is outside the defined margins for tolerance. It is considered that if this 
value is less than $30 \%$, the accuracy of the network for predicting the output value is satisfactory.

- Root Mean Square Error that - a measure for the deviation of the predicted from actual values. This is one of the most commonly used measures for differences between the provided values by the model and expected values. These individual differences are still called the prediction errors or residual values and mean Absolute Error (the average de- viation of predicted from actual values).

Nine multilayered neural networks with forward propagation, with one input layer, one hidden layer and one output layer, with different number of neurons in the hidden layer (2 to 10 neurons) were trained and tested and the optimal neural network was defined. Training was conducted through 1000000 eras or 1000000 cycles of learning. Table 1 shows the results obtained after the testing of all nine neural networks.

Table 1. Neural networks testing report

\begin{tabular}{|c|c|c|c|}
\hline Type of neural network & \% bad predictions & RMSE & MAE \\
\hline MLFN with 2 neurons & 41.18 & 1.67 & 1.27 \\
\hline MLFN with 3 neurons & 23.53 & 0.73 & 0.65 \\
\hline MLFN with 4 neurons & 0.00 & 0.48 & 0.39 \\
\hline MLFN with 5 neurons & 23.53 & 0.77 & 0.55 \\
\hline MLFN with 6 neurons & 29.41 & 0.71 & 0.58 \\
\hline MLFN with 7 neurons & 5.88 & 0.35 & 0.27 \\
\hline MLFN with 8 neurons & 35.29 & 1.51 & 1.01 \\
\hline MLFN with 9 neurons & 11.76 & 0.52 & 0.41 \\
\hline MLFN with 10 neurons & 41.17 & 1.37 & 1.02 \\
\hline
\end{tabular}

If the percentage of bad predictions is within the allowable limits (less than $30 \%$ ), then the optimal neural network is the network that has the lowest value of the root mean square error and mean absolute error obtained by testing [10]. Analyzing the results shown in Table 1 it can be concluded that the worst prediction would be obtained if adopted multilayered neural network is with 2 or 10 neurons in the hidden layer. Multilayered network with 7 neurons in hidden layer gives the lowest error and therefore this structure is adopted as the optimal for determination the fire resistance of analyzed columns. The predicted values obtained by trained neural network for the cases used for training and the calculated values for the fire resistance of the columns, expressed in hours, are compared in Figure 2.

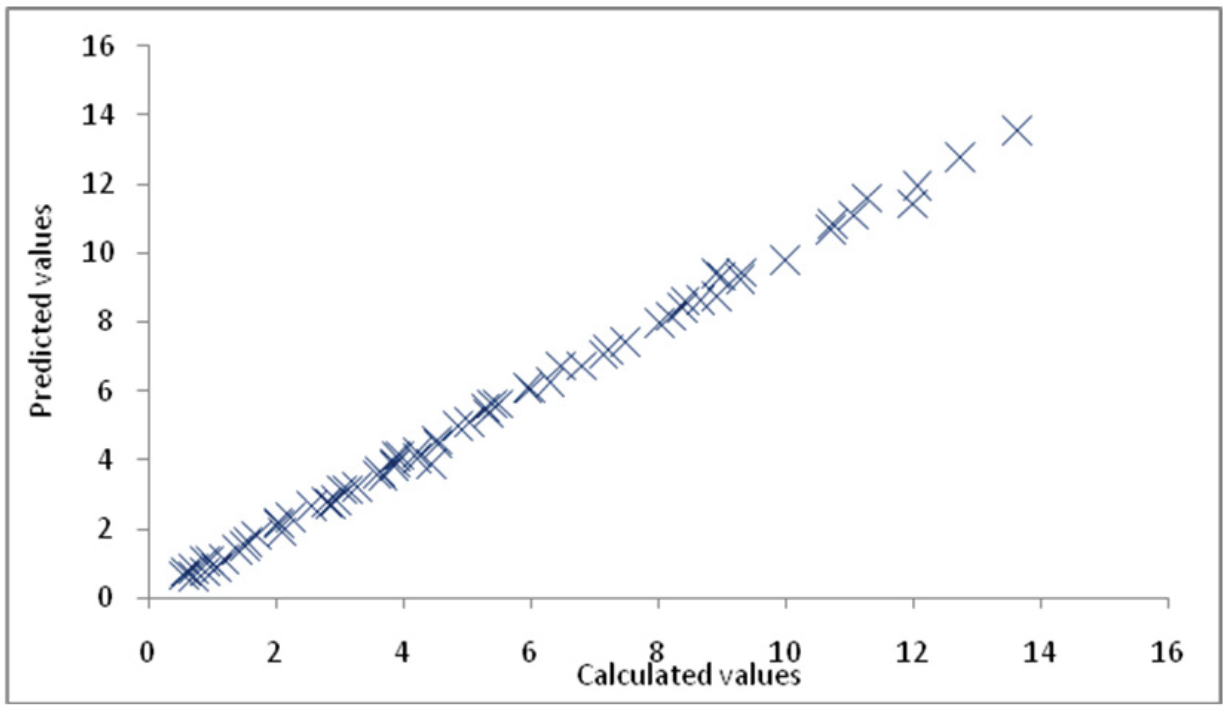

Figure 2: Comparison of calculated and predicted values for the fire resistance of composite columns, used for training the neural network 
The predicted values obtained by the trained neural network for the 17 cases that were not used for the training, but for the testing of the neural network, and the corresponding values calculated with the program FIRE, are compared in Figure 3.

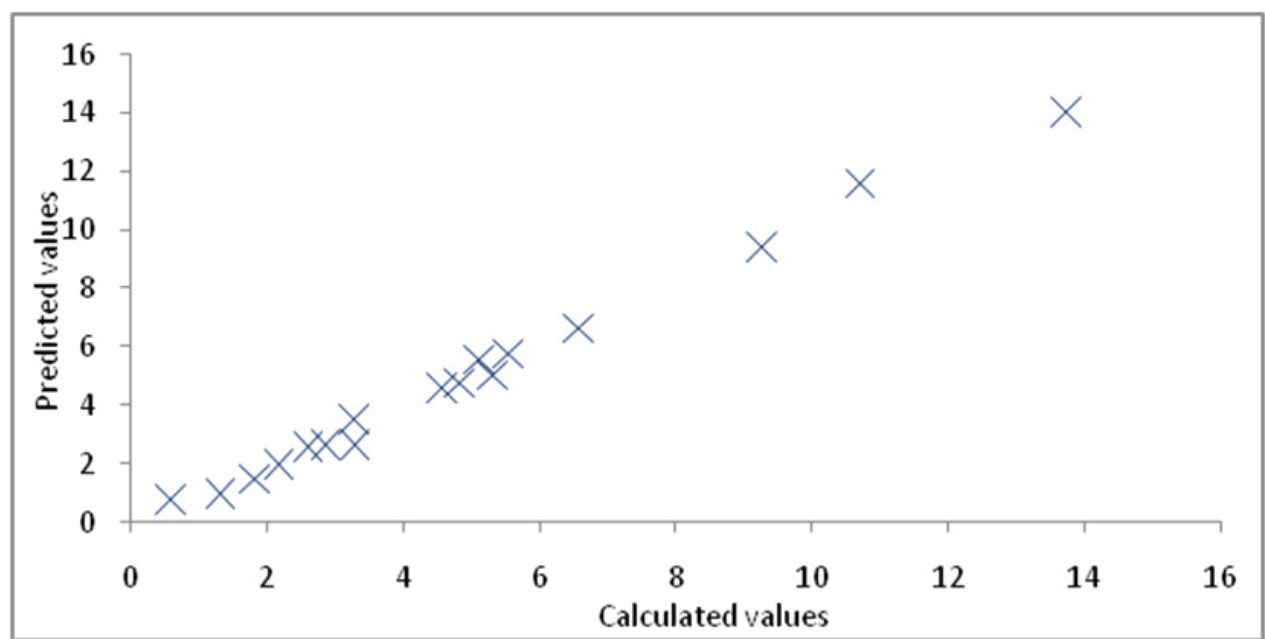

Figure 3: Comparison of calculated and predicted values of the fire resistance of composite $R C$ columns, used for testing the neural network

The histogram of the residual values (average deviation of the predicted value from the calculated value) of the predicted values for the fire resistance of columns for training and testing data, are presented on Figures 4 and 5. Most of the residual values are around 0 which is a good indicator of the accuracy of the model for predicting the fire resistance of this type of columns.

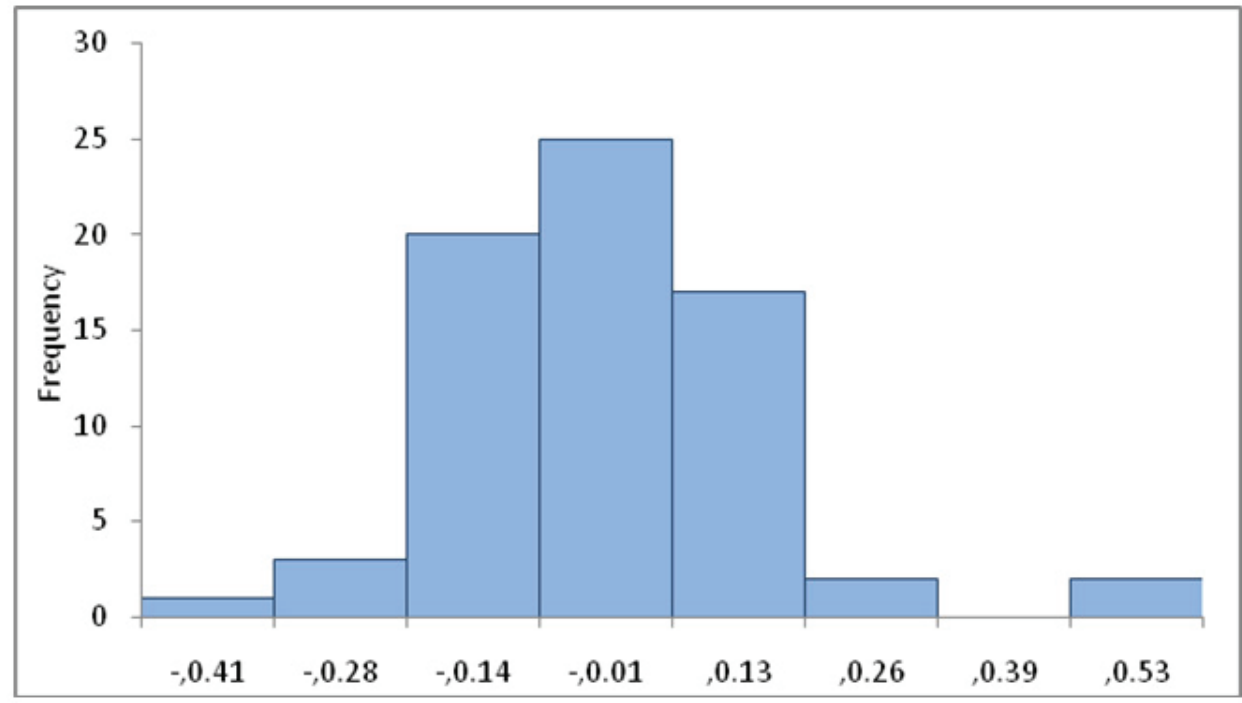

Figure 4: Histogram of the residual values of training data

Graphical presentation of the comparison of the actual (calculated with program FIRE) and the predicted fire resistance values (obtained by the neural network prognostic model) for 27 cases that were not included in the training and testing process, is given on Figure 6.

Based on the results obtained from the numerical analysis and the neural network prognostic model, fire resistance curves were constructed. These curves may be used for determination the fire resistance of composite steel concrete columns that were not previously analyzed. The fire resistance curves for the columns with dimensions $30 \times 50 \mathrm{~cm}$ and different types of cross section, constructed by both methods, are presented on Figure 7. From these curves, depending on the level of the axial force (load coefficient ) and the type of the cross section, the fire resistance of the column could be defined without any additional calculation. 


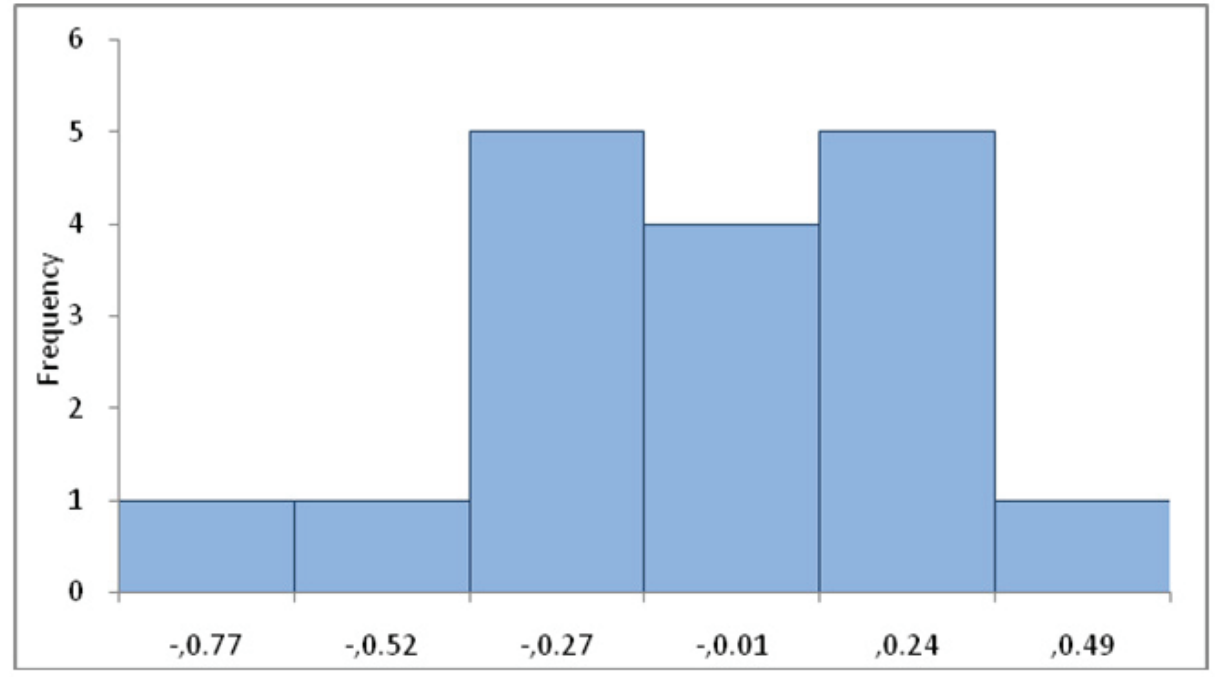

Figure 5: Histogram of the residual values of testing data

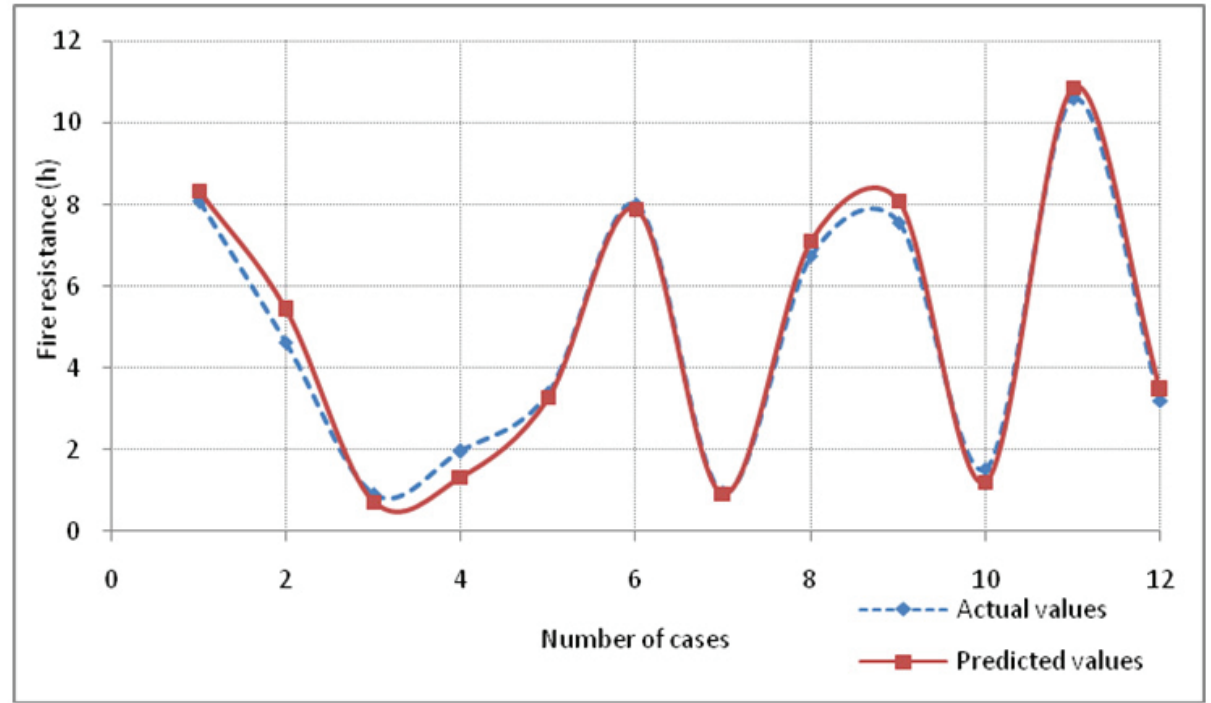

Figure 6: Calculated and predicted fire resistance values for cases that were not included in the training and testing process

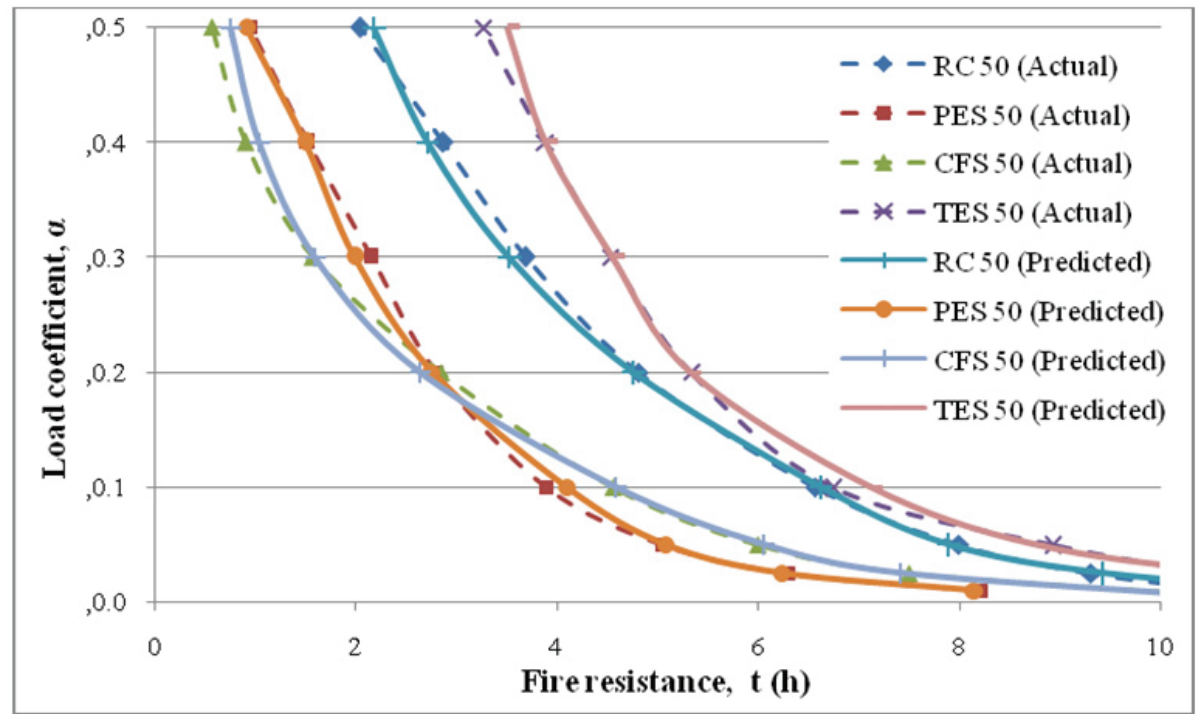

Figure 7: Comparison of calculated (actual) and predicted fire resistance curves for centrically loaded composite columns with cross section dimensions $30 \times 50 \mathrm{~cm}$ 
It can be seen that the corresponding curves constructed on the basis of the numerically achieved results and on the basis of the results from the neural network approach are similar and give close results.

\section{CONCLUSION}

The application of neural networks for prognostic modeling which can be used for predicting the fire resistance of structures and/or their elements is of huge importance for the construction design process. Most of the experimental models for determination the fire resistance are extremely expensive, and analytical models are quiet complicated and time consuming. That is why a modern type of analyses, such as modeling through neural networks, can help, especially in those cases where some prior analyses were already made.

The main goal of this research was to explain the simplicity and the positive aspects of the usage of neural networks for solving engineering problems. After the comparison of both methods it can be concluded that artificial neural networks present an excellent tool for prognostic modeling and can be used for determination the fire resistance of steel- concrete composite columns, especially in those cases when there are no (or very few) experimental and/or numerical results.

\section{REFERENCES}

1) Cvetkovska M.: „Nonlinear stress strain behavior of RC elements and plane frame structures exposed to fire", Ph. D. thesis, Civil Engineering Faculty in Skopje, Sts Cyril and Methodius University, Macedonia, 2002

2) Cvetkovska M., Milanović M., Jovanoska M., Čifliganec C.: „Parametric analysis of fire resistance of centrically loaded composite steel-concrete columns", 15th International Symposium of Macedonian Association of Structural Engineers - MASE, Ohrid, Macedonia, September 2013

3) Chen A. M., Lu H.-m., Hecht-Nielsen R.: "On the geometry of feedforward neural network error surfaces", Neural computations, 1993, pp. 910-927

4) Flood I. and Nabil K.: „Neural networks in civil engineering II: Systems and application.", Journal of Computing in Civil Engineering 8, no. 2,1994 , pp. 149-162
5) Flood I. and Paul C.: „Modeling construction processes using artificial neural networks", Automation in Construction, Volume 4, Issue 4, 1996, pp. 307-320

6) Flood I.: „Simulating the construction process using neural networks", Proceedings of the 7th ISARC - International Association for Automation and Robotics in Construction, Bristol, United Kingdom, 1990, pp. 374-382

7) Jeng DS, Cha DH and Blumenstein M.: „Application of Neural Networks in Civil Engineering Problems“, Proceedings of the International Conference on Advances in the Internet, Processing, Systems and Interdisciplinary Research (IPSI-2003), 2003

8) Knežević M.: „Risk management of civil engineering projects“, Ph. D. thesis, Civil Engineering Faculty, University in Belgrade, Serbia, 2005

9) Knežević M. and Zejak R.: "Neural networks - application for usage of prognostic model of the experimental research for thin reinforced-concrete columns", scientific research work, Materials and constructions, 2008.

10) Lazarevska M., Knezevic M., Cvetkovska M., Trombeva G. A. and Samardzioska T.: „Neural network's application for predicting the fire resistance of reinforced concrete columns“, Journal Gradjevinar. Vol.7, 2012, pp. 565-571

11) http://www.palisade.com/neuraltools/

Paper sent to revision: 07.02.2014.

Paper ready for publication: 15.03.2014. 